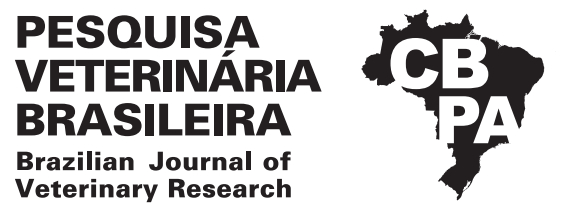

Pesq. Vet. Bras. 38(8):1528-1536, agosto 2018 DOI: 10.1590/1678-5150-PVB-5374

Artigo Original

Animais de Produção/Livestock Diseases

ISSN 0100-736X (Print)

ISSN 1678-5150 (Online)

\title{
Influência do polipirrol e dos níveis de salinidade na formação de biofilme em Aeromonas spp. ${ }^{1}$
}

\author{
Isabelle Caroline Pires ${ }^{2 *}$, Naiana B. Freire², Antônio W.C. Fernandes ${ }^{2}$, \\ Renata F.S. Souza², Fernando A.G. Silva Jr², Helinando P. Oliveira² e Mateus M. Costa²
}

ABSTRACT.- Pires I.C., Freire N.B., Fernandes A.W.C., Souza R.F.S., Silva Jr F.A.G., Oliveira H.P. \& Costa M.M. 2018. [Influence of polypyrrole and salinity levels on biofilm formation in Aeromonas spp.]. Influência do polipirrol e dos níveis de salinidade na formação de biofilme em Aeromonas spp. Pesquisa Veterinária Brasileira 38(8):1528-1536. Laboratório de Microbiologia e Imunologia Animal, Universidade Federal do Vale do São Francisco, Rodovia BR-407 Km 12, Lote 543, Projeto de Irrigação Nilo Coelho, C1, Petrolina, PE 56300-000, Brazil. E-mail: isabellecpires@hotmail.com

Bacteria of the genus Aeromonas are highly disseminated pathogens in the aquatic environment, responsible for great economic losses in the pisciculture of several countries. They are opportunistic microorganisms and their pathogenicity is linked to some virulence factors, such as biofilm formation. Saline stress is one of the factors that favor the formation of these colonies and, consequently, the increase of infections. These infections, when associated with biofilm, are even more resistant to antimicrobials. In this context, polypyrrole stands out as an antimicrobial alternative because it has several therapeutic attributes and does not present toxicity to organisms. Thus, the objective of this study was to evaluate the susceptibility profile and the biofilm formation capacity of Aeromonas spp. associated with different levels of salinity and polypyrrole. The antibacterial activity of the isolates was determined and motility assays were performed with bacteria bearing the fla gene. The ability of sodium chloride and polypyrrole to interfere with biofilm formation has also been demonstrated. The results were evidenced with scanning electron microscopy. Concentrations of 2 and $3 \%$ of $\mathrm{NaCl}$ inhibited bacterial motility. In the biofilm formation, $83 \%$ of the bacterial isolates induced production at the concentration of $0.25 \%$. Polypyrrole caused the death of all the isolates tested at the concentration of $125 \mu \mathrm{g} / \mathrm{mL}$. In addition, this compound decreased bacterial motility at concentrations of 0.25 to $3 \%$, and no biofilm was produced. These results show that the different levels of $\mathrm{NaCl}$ influence in the formation of the biofilm favoring the persistence of the infection. This study also highlighted the potential of polypyrrole as a bactericidal agent, being an effective alternative to antimicrobial drugs for the treatment of infections caused by Aeromonas spp.

INDEX TERMS: Biofilm, Aeromonas spp., gene fla, motility, pisciculture, aquiculture, polymer, resistance, bacterioses.

\footnotetext{
RESUMO.- Bactérias do gênero Aeromonas são patógenos altamente disseminados no ambiente aquático, responsáveis por grandes perdas econômicas na piscicultura de diversos países. São micro-organismos oportunistas e sua patogenicidade está ligada a alguns fatores de virulência, como a formação de biofilme. 0 estresse salino é um dos fatores que favorecem a formação dessas colônias e, consequentemente, o aumento

${ }^{1}$ Recebido em 29 de agosto de 2017.

Aceito para publicação em 5 de setembro de 2017.

${ }^{2}$ Laboratório de Microbiologia e Imunologia Animal, Universidade Federal do Vale do São Francisco, Petrolina, PE 56330-990, Brasil. *Autor para correspondência: isabellecpires@hotmail.com
}

de infecções. Essas infecções quando estão associadas ao biofilme são ainda mais resistentes aos antimicrobianos. Nesse contexto, o polipirrol destaca-se como uma alternativa antimicrobiana por possuir vários atributos terapêuticos e não apresentar toxicidade aos organismos. Dessa forma, o objetivo desse estudo foi avaliar o perfil de susceptibilidade e a capacidade de formação de biofilme dos isolados de Aeromonas spp. associados aos diferentes níveis de salinidade e polipirrol. Determinou-se a atividade antibacteriana dos isolados e ensaios de motilidade foram realizados com bactérias que carreavam o gene fla. Também verificou-se a capacidade do cloreto de sódio e polipirrol em interferir na 
formação do biofilme. Os resultados foram evidenciados com a microscopia eletrônica de varredura. As concentrações de 2 e $3 \%$ de $\mathrm{NaCl}$ inibiram a motilidade bacteriana. Na formação do biofilme, 83\% dos isolados bacterianos induziram a produção na concentração de $0,25 \%$. O polipirrol causou a morte de todos os isolados testados na concentração de $125 \mu \mathrm{g} / \mathrm{mL}$. Além disso, esse composto diminuiu a motilidade bacteriana nas concentrações de 0,25 a $3 \%$, sendo que em relação à produção de biofilme, não houve interferência. Esses resultados evidenciam que os diferentes níveis de $\mathrm{NaCl}$ influenciam na formação do biofilme favorecendo a persistência da infecção. Este estudo também realçou a potencialidade do polipirrol como agente bactericida, sendo uma alternativa eficaz às drogas antimicrobianas para o tratamento das infecções causadas por Aeromonas spp.

TERMOS DE INDEXAÇ̃̃O: Biofilme, Aeromonas spp., gene fla, motilidade, piscicultura, aquicultura, polímero, resistência, bacterioses.

\section{INTRODUÇÃO}

A piscicultura vem se tornando significativa para o desempenho geral da economia brasileira (Kubitza et al. 2012). Em 2016, a América Latina e o Caribe produziram cerca de 3,7 milhões de toneladas de peixe em aquicultura, representando um aumento de $39,9 \%$ para o setor, em comparação ao período de 2013 a 2015. Seguindo essa tendência de crescimento, o Brasil deve registrar um crescimento de $104 \%$ na produção da pesca e aquicultura até o ano de 2025 (FAO 2016).

0 ambiente aquático é dotado de uma microbiota em equilíbrio, composta por bactérias benéficas para o animal de cultivo, bem como de bactérias patogênicas obrigatórias e oportunistas. Entretanto, o aumento da prevalência de enfermidades na piscicultura influencia negativamente no desenvolvimento econômico, afetando o setor de diversos países (Schulze et al. 2006). Um dos principais agentes causadores dessas perdas são as bactérias do gênero Aeromonas, que são um grupo de patógenos Gram negativos altamente disseminados pelos ambientes aquícolas (Gram et al. 1999). Esses micro-organismos podem provocar furunculose em animais aquáticos imunossuprimidos, podendo resultar em necrose dos tecidos e septicemia hemorrágica (Janda \& Abbott 2010).

A patogenicidade desses micro-organismos está associada aos diversos fatores de virulência, entre eles, a formação de biofilme, que são estruturas de proteção formada pelas bactérias (Tiba et al. 2009). Os biofilmes são constituídos por uma organização de colônias vivas que, quando se aderem a uma superfície, produzem e se envolvem em uma matriz de polímeros extracelulares (exopolissacarídeos), resultando em um processo irreversível. Sendo assim, esses micro-organismos passam de um estado planctônico para séssil (Clutterbuck et al. 2007). Essa patogenicidade também está relacionada com a presença de um flagelo, codificados pelos genes fla (flagelo polar) e laf (flagelo lateral), que desempenha um importante papel na adesão bacteriana de Aeromonas, favorecendo a formação do biofilme (Huang et al. 2015).

No ambiente aquático, as bactérias do gênero Aeromonas estão constantemente cercadas de uma variedade de condições estressantes, como a hiper-salinidade. Dessa forma, a capacidade de adaptação é crucial para sua sobrevivência (Pianetti et al. 2012). Para se adaptar às mudanças de osmolaridade no ambiente, esses micro-organimos acumulam solutos orgânicos que lhes conferem proteção contra efeitos deletérios da baixa atividade da água (Delamare et al. 2003). Alguns autores relatam que eles podem sobreviver em concentrações crescentes de cloreto de sódio $(\mathrm{NaCl})$ de até $6 \%$, beneficiando o crescimento de colônias com a formação do biofilme (Martin-Carnahan \& Joseph 2005, Pianetti et al. 2008, Janda \& Abbott 2010). A presença dos flagelos contribui mais ainda para essa formação (Santos et al. 2011). Sendo assim, diferentes níveis de salinidade, além de modular a formação dos biofilmes, também controlam a motilidade desses micro-organismos, favorecendo sua sobrevivência (Jahid et al. 2015).

Devido à distribuição ubíqua das cepas de Aeromonas em ambiente aquícola e sua capacidade de desenvolver resistência antimicrobiana única ou múltipla, esses micro-organismos são considerados patógenos emergentes (Naviner et al. 2011). Dessa forma, o uso indiscriminado de antimicrobianos favorece o crescimento de cepas resistentes de uma forma irreversível (Pereira et al. 2013). As infecções quando estão associadas com a formação de biofilme são ainda mais resistentes aos antibióticos (Ceri et al. 2010), uma vez que os exopolissacarídeos atuam como uma barreira física para esses medicamentos (Clutterbuck et al. 2007). Nesse contexto, a busca por alternativas viáveis para o combate à resistência bacteriana vem sendo constantemente explorada. 0 polipirrol (PPy) é um polímero eletricamente condutor e biocompatível, que tem sido progressivamente estudado por possuir diversos atributos terapêuticos. Os polímeros são macromoléculas formadas por unidades repetitivas, sintetizadas a partir de moléculas simples denominadas monômeros (Fig.1) (Varesano et al. 2015).

0 processo de morte celular depende da adsorção eficiente das cadeias de polipirrol na superfície de células (Wang et al. 2004). A adsorção da substância na superfície da parede celular e saída de componentes intracelulares, causam liberação de íons de potássio, no qual provocam a morte bacteriana (Varesano et al. 2013). Essa forte interação eletrostática entre espécies de cargas opostas permite sua aplicação como agente bactericida (Wong et al. 1994). Dessa forma, o uso desse polímero releva-se como uma alternativa relevante contra as bactérias resistentes, uma vez que possui atividade antimicrobiana (Wong et al. 1994, Zhang et al. 2014), tem um processo de síntese simples e não provoca efeito adverso sobre as culturas celulares e os animais (Wang et al. 2004). Além disso, a substância tem rápida atuação (Silva Junior et al. 2016) e capacidade de detecção e controle do biofilme por medições

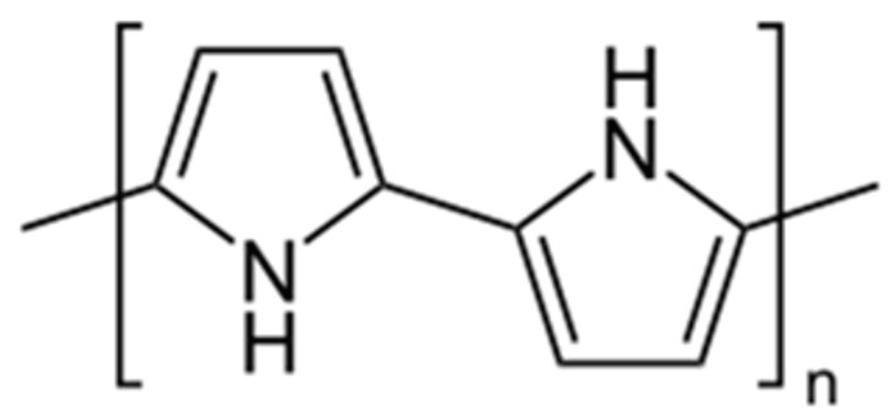

Fig.1. Estrutura química do monômero do polipirrol. 
eletroquímicas (Zheng et al. 2013), o que pode contribuir na eficácia dos antibióticos convencionais (Zhang et al. 2014).

Portanto, o presente estudo visa avaliar se há interferência do $\mathrm{NaCl}$ e PPy na formação do biofilme de Aeromonas spp., bem como a susceptibilidade das bactérias a essas substâncias.

\section{MATERIAL E MÉTODOS}

Amostras. Os isolados de Aeromonas spp. foram provenientes da bacterioteca do Laboratório de Microbiologia e Imunologia Animal, Universidade Federal do Vale do São Francisco. As bactérias foram obtidas de tilápias do Nilo (Oreochromis niloticus) com alguma anormalidade clínica aparente de infecção bacteriana, oriundas de tanques e açudes em propriedades do Agreste e do Sertão de Pernambuco. Utilizou-se um total de 17 amostras que encontravam-se dispostas na bacterioteca nas quais foram previamente identificadas por meio de características morfológicas, tintoriais, bioquímicas e sequenciamento de parte do gene 16S rRNA.

Obtenção do PPy. 0 polipirrol foi disponibilizado pelo Laboratório de Espectroscopia de Impedância e Materiais Orgânicos (LEIMO), localizado no Campus Juazeiro/BA da Universidade Federal do Vale do São Francisco (Univasf). Essa substância foi purificada sob pressão reduzida, segundo a metodologia descrita por Kang et al. (2005), no qual 1,08g de sodium dodecyl sulfate (SDS) foi imerso em $100 \mathrm{~mL}$ de água milli- $Q$, acrescido com $500 \mu \mathrm{L}$ de pirrol (Sigma Aldrich ${ }^{\circledR}$ ). Essa solução foi mantida sob agitação intensa durante 45 minutos. Em seguida, uma solução aquosa $(50 \mathrm{~mL})$ de persulfato de amônio $(0,256 \mathrm{~g})$ foi adicionada lentamente por gotas e mantida sob agitação intensa por 35 minutos. A solução final foi mantida a $4^{\circ} \mathrm{C}$ por 24 horas. 0 PPy encontrava-se solubilizado em uma concentração de $2 \mathrm{mg} / \mathrm{mL}$. Para sua utilização neste estudo, foi realizada uma diluição de 1:1 (solução estoque de $1 \mathrm{mg} / \mathrm{mL}$ ) com água destilada devidamente esterilizada.

Concentração inibitória mínima (CIM) e concentração bactericida mínima (CBM). A análise da atividade antimicrobiana foi realizada baseada no protocolo do CLSI (2014), que consiste na distribuição de $200 \mu \mathrm{L}$ de caldo Muller-Hinton (MH Kasvi ${ }^{\circledR}$, Itália) em microplacas de poliestireno de fundo chato com 96 poços. Posteriormente, uma alíquota de $200 \mu \mathrm{L}$ do PPy foi distribuída nos primeiros poços da microplaca e, após a homogeneização, a solução foi transferida para o segundo poço, e assim sucessivamente. Uma vez realizadas as diluições seriadas, foram obtidas as seguintes concentrações finais: $500,250,125,62.5,31.25,15.62,7.81,3.9 \mu \mathrm{g} / \mathrm{mL}$.

Para a solução salina, as concentrações foram calculadas a partir dos valores intermediários de salinidade da água do mar e do rio, utilizando as seguintes concentrações: $0 ; 0.1,0.25,0.5,1$, 2 e 3\% (Jahid et al. 2015).

Na preparação do inóculo bacteriano, $5 \mathrm{~mL}$ de solução salina foram utilizados para obtenção de uma suspensão bacteriana com densidade óptica de $0,104 \mathrm{~nm}\left(10^{8}\right.$ Unidades Formadoras de Colônias por $\mathrm{mL}$ ), mensurada em um espectrofotômetro ultravioleta-visível (UV-vis) Hach, no comprimento de onda de 580nm. Dessa suspensão, uma alíquota de $100 \mu \mathrm{L}$ foi transferida para tubos contendo $9,9 \mathrm{~mL}$ de caldo $\mathrm{MH}$, que em seguida, $10 \mu \mathrm{L}\left(10^{4} \mathrm{UFC}\right)$ da solução bacteriana foram inoculados nos poços da microplaca contendo as substâncias homogeneizadas. Para o controle negativo, foi utilizado caldo $\mathrm{MH}$ e, como controle da viabilidade bacteriana, utilizou-se poços com caldo $\mathrm{MH}$ e o inóculo bacteriano de cada amostra. As microplacas ficaram incubadas em uma estufa bacteriológica a $28^{\circ} \mathrm{C}$ por 24 horas. Todo ensaio foi realizado em triplicata.

Após a incubação, uma alíquota de $10 \mu \mathrm{L}$ foi colocada em uma placa de ágar MH com o auxílio de um replicador. A CBM foi determinada a partir da leitura visual, considerando a menor concentração da substância capaz de matar a bactéria. Para a CIM, foram adicionados $20 \mu \mathrm{L}$ de CTT (Cloreto de trifeniltetrazólio). A mudança de coloração é indicativa da viabilidade da bactéria. Para esse ensaio, utilizou-se um total de 17 amostras que foram previamente identificadas como Aeromonas spp.

Ensaio de motilidade. 0 ensaio de motilidade foi realizado baseado no método descrito por Kuchma et al. (2015), que consistiu na preparação de um ágar composto de 3\% de ágar, $1 \%$ de triptona, $5 \%$ de extrato de levedura e $5 \%$ de cloreto de sódio para $100 \mathrm{~mL}$ de água destilada. Diversas dessas soluções foram preparadas adicionando as diluições de $\mathrm{NaCl}$ e PPy em $0,0.1 ; 0.25,0.5,1$, 2 e 3\%. Para o controle positivo da bactéria, as substâncias não foram acrescentadas na solução.

Em placas de petri, foram distribuídos 20mL de Trypticase Soy Agar (TSA Himedia ${ }^{\circledR}$ Mumbai, India) e, após sua solidificação, $20 \mathrm{~mL}$ do ágar preparado inicialmente foram cuidadosamente distribuídos sobrepondo o TSA, formando assim duas camadas de ágar. Com ajuda de uma alça bacteriológica, uma colônia de Aeromonas spp. que carreava o gene fla, foi inoculada em $3 \mathrm{~mL}$ de Trypticase Soy Broth (TSB Himedia ${ }^{\circledR}$ ) e levada a estufa a $28^{\circ} \mathrm{C}$ por 24 horas. Dessa suspensão, inoculou-se $25 \mu \mathrm{L}$ no centro da placa de petri contendo as soluções e levou-se a estufa bacteriológica a $28^{\circ} \mathrm{C}$ por 24 horas. Após o decorrido tempo, foi observado a migração das células bacterianas, avaliando o halo de crescimento na placa. Para esse ensaio, foram utilizadas apenas as duas amostras de Aeromonas spp. previamente caracterizadas como carreadoras do gene fla.

\section{Atividade sobre a produção de biofilme}

Quantificação. Para quantificação do biofilme, a metodologia adotada foi descrita por Christensen et al. (1985). Foram selecionados todos os isolados bacterianos $(\mathrm{n}=17)$ previamente identificados como Aeromonas spp.

Em tubos de ensaio contendo 3mL de TSB, colocou-se o inóculo bacteriano e, em seguida, levados à estufa bacteriológica a $28^{\circ} \mathrm{C}$ por 24 horas. De cada amostra, retirou-se $5 \mu \mathrm{L}$, adicionando-os aos poços das microplacas estéreis, já contendo $195 \mu \mathrm{L}$ de TSB, sendo novamente incubados a $28^{\circ} \mathrm{C}$ por 24 horas. Após o decorrido tempo, o conteúdo da microplaca foi descartado e realizou-se três lavagens com $200 \mu \mathrm{L}$ de água destilada esterilizada.

Após as lavagens, os poços foram corados com $100 \mu \mathrm{L}$ de violeta de genciana $0,25 \%$ por três minutos em temperatura ambiente e lavados novamente três vezes com $200 \mu \mathrm{L}$ de água destilada. Por fim, utilizou-se $200 \mu \mathrm{L}$ de álcool-acetona (8:2) para diluição dos cristais. Em um leitor de microplacas Expert Plus-UV Asys, a absorbância foi mensurada em $620 \mathrm{~nm}$, com o intuito de determinar a produção de biofilme bacteriano de acordo com os valores de densidade óptica obtidos na leitura (Quadro 1).

Interferência na formação do biofilme. Para avaliar a capacidade de interferência do $\mathrm{NaCl}$ e PPy sobre o biofilme de Aeromonas

Quadro 1. Classificação dos isolados de Aeromonas spp. quanto à produção de biofilme

\begin{tabular}{cc}
\hline Classificação & Critério \\
\hline Negativo & $\mathrm{DO}_{\mathrm{A}}<\mathrm{DO}_{\mathrm{CN}}$ \\
Fraco & $\mathrm{DO}_{\mathrm{CN}}<\mathrm{DO}_{\mathrm{A}}<2 \times \mathrm{DO}_{\mathrm{CN}}$ \\
Moderado & $2 \times \mathrm{DO}_{\mathrm{CN}}<\mathrm{DO}_{\mathrm{A}}<4 \times \mathrm{DO}_{\mathrm{CN}}$ \\
Forte & $\mathrm{DO}_{\mathrm{A}}>4 \times \mathrm{DO} \mathrm{CN}_{\mathrm{CN}}$
\end{tabular}

$\mathrm{DO}_{\mathrm{A}}=$ Densidade óptica da amostra teste, $\mathrm{DO}_{\mathrm{CN}}=$ Densidade óptica do controle negativo. 
spp., foi adaptada a metodologia de Nostro et al. (2007). Dentre os isolados quantificados, apenas os positivos para formação de biofilme foram utilizados nessa metodologia. Cada amostra bacteriana foi cultivada em tubos contendo $3 \mathrm{~mL}$ de TSB e incubada em estufa a $28^{\circ} \mathrm{C}$. Após 24 horas, $100 \mu \mathrm{L}$ dessa suspensão foram distribuídos nos poços das microplacas já contendo $100 \mu \mathrm{L}$ da substância a ser testada (PPy ou $\mathrm{NaCl}$ ). As concentrações utilizadas foram equivalentes à metade do valor de CBM observado na micro diluição em placa. Todo ensaio foi realizado em triplicata. A microplaca foi incubada a $28^{\circ} \mathrm{C}$ por 24 horas. Após esse período, o conteúdo das microplacas foi descartado em recipiente adequado para retirar as bactérias planctônicas. Foram realizadas três lavagens com $200 \mu \mathrm{L}$ de água destilada auto clavada. Posteriormente, foram adicionados $100 \mu \mathrm{L}$ de violeta de genciana $0,25 \%$ por três minutos em temperatura ambiente e lavados novamente três vezes com $200 \mu \mathrm{L}$ de água destilada. Então, foram adicionados $200 \mu \mathrm{L}$ de álcool-acetona (8:2) para realizar a leitura da densidade óptica no leitor de microplacas Expert Plus-UV Asys, mensurada em $620 \mathrm{~nm}$.

Microscopia eletrônica de varredura (MEV). Para a caracterização morfológica das bactérias e do biofilme na presença das soluções de PPy e $\mathrm{NaCl}$ dos isolados selecionados de Aeromonoas spp., realizou-se a microscopia eletrônica de varredura, seguindo o protocolo de Freitas et al. (2010). Para as soluções de $\mathrm{NaCl}$ foi realizada o ensaio nas concentrações de $0,25 \%$. Para o PPy, testou-se o valor da CBM e 0,5 CBM da substância.

Realizou-se a inoculação da bactéria em tubos contendo $3 \mathrm{~mL}$ de TSB e foram levados a estufa bacteriológica a $28^{\circ} \mathrm{C}$ por 24 horas. Decorrido este tempo, foi feito o protocolo para interferência da formação do biofilme, descrito anteriormente. Ao final do processo, acrescentou-se uma pequena placa de aço inoxidável, a qual serve como suporte para fixação da bactéria. Após 24 horas, as placas de inox foram imersas em glutaraldeido a $1 \%$ por duas horas e meia e, posteriormente colocadas em solução crescente de etanol (50\%; $70 \%$; $80 \%$; $95 \%$ e $100 \%$ ) a cada 20 minutos. Ao final, as placas foram colocadas em acetona a $100 \%$ por 5 minutos e a temperatura ambiente para secagem. Para análise no microscópio, o suporte de inox foi colocado em grades circulantes (stabs) (3,2mm de diâmetro) e recobertas por uma fina camada de ouro (suporte mecânico). Na sequência, as amostras foram inseridas no MEV Tecnai $G^{2}$, modelo VEGA 3 - TESCAN, obtendo imagens de 5 e $10 \mathrm{kV}$.

Análise estatística. Os valores obtidos para o ensaio de motilidade e interferência na formação do biofilme, foram submetidos ao teste One-Way ANOVA (no parametric) com o pós-teste de Tukey. 0 programa utilizado foi GraphPad Prism versão 5.0 para Windows. As medidas foram ditas com diferença estatística, utilizando o intervalo de confiança de 95\%, com valor de $\mathrm{p}<0,05$.

\section{RESULTADOS E DISCUSSÃO \\ Cloreto de sódio \\ CIM e CBM. Nenhuma das bactérias apresentou sensibilidade} ao $\mathrm{NaCl}$, o que era de se esperar, uma vez que os autores Pianetti et al. (2008) indicaram que Aeromonas hydrophila possui alta tolerância ao sal (em níveis de até 6\%). Em concordância, Martin-Carnahan \& Joseph (2005) relataram que as Aeromonas são um dos principais patógenos encontrados na água e podem sobreviver em concentrações crescentes de cloreto de sódio. De acordo com Delamare et al. (2003), a tolerância ao sal associa-se ao aumento da concentração intracelular de solutos que podem ser sintetizados por essas bactérias mantendo o turgor celular. Portanto, os maiores níveis utilizados nesse estudo (3\%) não provocaram a morte bacteriana em nenhum dos isolados testados, evidenciando assim a sua tolerância ao $\mathrm{NaCl}$.

Ensaio de motilidade. No presente estudo, a motilidade bacteriana foi observada em todas as placas controle, sem a adição das substâncias, com um halo de crescimento médio de 3,6 cm (Fig.2A). De acordo com os autores Kirov et al. (2002) e Wu et al. (2015), o flagelo polar é codificado pelo gene fla e permite motilidade a esses micro-organismos. 0 halo de crescimento foi observado em todas as placas controle, o que evidencia que as bactérias testadas possuem um alto índice de virulência, uma vez que a motilidade está diretamente relacionada com a patogenicidade da infecção. Essa motilidade é importante, não só pela multiplicação bacteriana, mas para a ligação delas às superfícies bióticas ou abióticas (Santos et al. 2011). Portanto, o flagelo polar desempenha um papel importante na virulência de organismos patogênicos, entre eles, as bactérias do gênero Aeromonas.

As concentrações de $0,1 \%$ e $0,5 \%$ de $\mathrm{NaCl}$ apresentaram em média 3,3 cm do halo de motilidade bacteriano, enquanto as concentrações de 0,25\% e 1\% apresentaram uma média de $3,7 \mathrm{~cm}$ e 2,9 cm, respectivamente. Para as concentrações

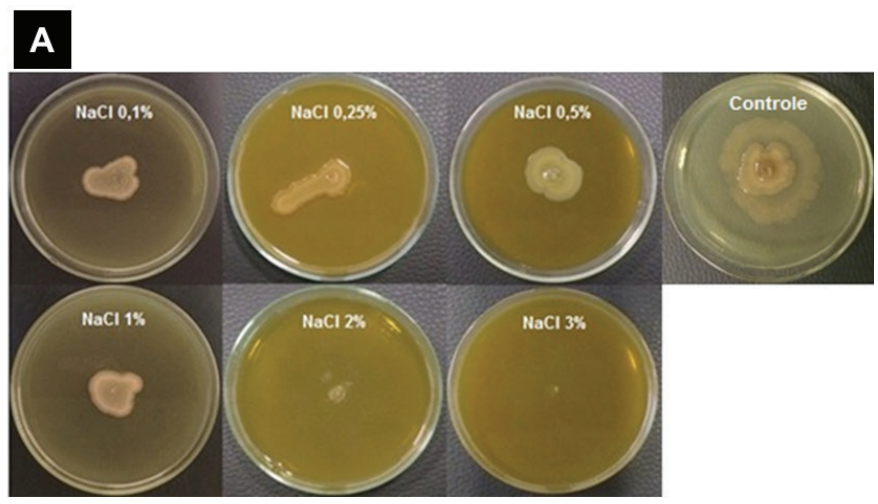

B

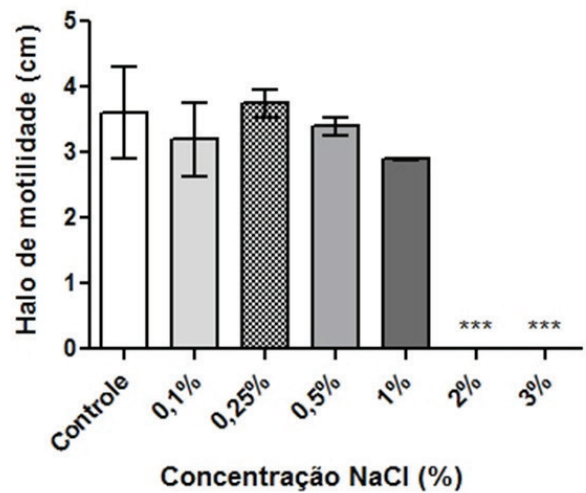

Fig.2. Ensaio de motilidade das bactérias Aeromonas spp. que carream o gene fla, na presença de diferentes concentrações de $\mathrm{NaCl}: 0,1 ; 0,25 ; 0,5 ; 1 ; 2$ e 3\%, respectivamente. (A) Análise fenotípica do halo de motilidade dos isolados de Aeromonas spp., evidenciando a migração dessas bactérias a partir do local inoculado. (B) Halo de motilidade ( $\mathrm{cm}$ ) da média dos isolados de Aeromonas spp. em função das diferentes concentrações de $\mathrm{NaCl}$, quando comparados ao controle (sem a substância). Os dados são apresentados com média + desvio padrão e as diferenças entre os grupos foram comparadas usando One-way ANOVA com pós-teste Tukey. ${ }^{* * *}$ Nível de significância $\mathrm{p}<0,001$. 
maiores (2 e 3\%), não houve formação do halo de motilidade no local inoculado, apresentando uma diferença significativa $(\mathrm{p}<0,05)$ em relação ao controle (Fig.2B).

Portanto, é evidente que o estresse osmótico atua na fisiologia bacteriana, induzindo a diminuição da sua motilidade e, consequentemente, a sua patogenicidade. Segundo Lowry et al. (2014), o processo conhecido como quimiotaxia é caracterizado pela capacidade que as bactérias têm de mover-se em busca de nutrientes ou ambientes mais favoráveis para sua sobrevivência. Isso proporciona uma grande vantagem evolutiva para as bactérias, uma vez que possibilita a essas se adaptarem a uma variedade de ambientes, permitindo que respondam às condições favoráveis ou desfavoráveis. Conforme Pianetti et al. (2012), a exposição prolongada de $A$. hydrophila a condições ambientais subótimas, geralmente associadas à temperatura e concentração de sal, diminuem a capacidade de aderência, especialmente quando concentrações acima de 3\% de $\mathrm{NaCl}$ são atingidas. Sendo assim, a presença do gene fla não é o único fator determinante para a motilidade e sim a dependência de condições favoráveis para a expressão do mesmo. A inibição evidenciada neste ensaio, deve-se provavelmente ao estresse osmótico que pode ter influenciado na fisiologia bacteriana e, consequentemente, nos seus fatores de virulência, reduzindo assim, a motilidade. No estudo realizado por Jahid et al. (2015) com A. hydrophila, foi observada motilidade nas concentrações de $0,1 \%$ a $0,25 \%$, sendo que nas concentrações de 0,5 a $3 \%$ o crescimento foi diminuindo. Em concordância, Marcel et al. (2002) relatam que o isolamento de Aeromonas spp. é mais elevada com baixa salinidade e menor durante os períodos secos, quando a salinidade está maior do que $1 \%$.

\section{Atividade sobre a produção de biofilme}

Quantificação. Não foi possível caracterizar nenhuma cepa como forte ou moderada produtora de biofilme. Apenas $35 \%$ dos isolados $(n=6)$ foram classificados como fracos formadores de biofilme, os quais foram submetidos aos ensaios de interferência, por representarem os isolados passíveis de avaliação mais precisa. Os autores Li et al. (2011) relataram que o gênero Aeromonas tem a capacidade de forte aderência quanto à sua quantificação em 24h. Porém, isso não foi observado nesse presente estudo, uma vez que nenhum dos isolados apresentou-se como forte produtor de biofilme. Isso pode ser explicado pelo estudo feito por Jacques et al. (2010) que evidencia que a formação de biofilme frente as diferentes condições ambientais, pode influenciar em várias funções biológicas. Dessa forma, como as bactérias não sofreram nenhum tipo de ameaça à sua viabilidade, assim como não encontraram nenhuma condição favorável para sua multiplicação, não tiveram a necessidade de formar biofilme. Já no estudo realizado por Santos et al. (2011), 18\% das cepas de A. caviae foram classificadas como formadoras de biofilme fracas a moderadas. Segundo esses autores, estruturas como flagelo e pili, também desempenham um papel significativo na formação de biofilme por várias espécies bacterianas.

Interferência na formação do biofilme. No ensaio realizado com $\mathrm{NaCl}$, algumas diluições foram capazes de aumentar a produção de biofilme nos isolados testados. Nas diluições de $0,1 \%$ a $0,5 \%$, a salinidade intensificou a formação de biofilme, alterando as bactérias que eram fracas formadoras de biofilme para moderadas (Quadro 2). Entre esses, 83\% apresentaram aumento na produção de biofilme quando submetidos ao cultivo em meio contendo $0,25 \%$ de $\mathrm{NaCl}$, apresentando uma diferença significativa $(\mathrm{p}<0,01)$ na análise estatística (Fig.3). Isso foi evidenciado com a microscopia eletrônica de varredura, onde observou-se que na concentração de $0,25 \%$ houve um maior agrupamento bacteriano, demonstrando o aumento da formação do biofilme (Fig.4). Já as concentrações de 1 a 3\% não interferiram na formação do biofilme, permanecendo os isolados testados como fracos produtores de biofilme.

$\mathrm{O}$ isolado utilizado foi previamente classificado como fraco formador de biofilme (amostra controle) e, quando em contato com $\mathrm{NaCl}$, alterou-se para moderado. Esse resultado corrobora com o estudo realizado por Jahid et al. (2015), onde a salinidade de $0,25 \%$ estimulou o crescimento do biofilme de $A$. hydrophila. 0 cloreto de sódio em diferentes concentrações favorece a formação de colônias bacterianas, aumentando assim a produção de biofilme. Isso tem sido relatado em alguns patógenos como Lysteria monocytogenes, Salmonella typhimurium, Escherichia coli e Staphylococcus

\section{Quadro 2. Estado de formação de biofilme em isolados de Aeromonas spp. após o tratamento com diferentes concentrações de $\mathrm{NaCl}(\%)$}

\begin{tabular}{cccccccc}
\hline \multirow{2}{*}{ Isolados } & \multirow{2}{*}{ Quantificação } & \multicolumn{6}{c}{ Concentrações de NaCl } \\
\cline { 3 - 8 } & & $0,1 \%$ & $0,25 \%$ & $0,5 \%$ & $1 \%$ & $2 \%$ & $3 \%$ \\
\hline A1 & FRA & MOD & MOD & MOD & FRA & FRA & FRA \\
\hline A2 & FRA & MOD & MOD & MOD & FRA & FRA & FRA \\
\hline A3 & FRA & MOD & MOD & MOD & FRA & FRA & FRA \\
\hline A4 & FRA & MOD & MOD & MOD & FRA & FRA & FRA \\
\hline A5 & FRA & FRA & MOD & FRA & FRA & FRA & FRA \\
\hline A6 & FRA & FRA & FRA & FRA & FRA & FRA & FRA \\
\hline
\end{tabular}

FRA = Fraco, MOD = Moderado.

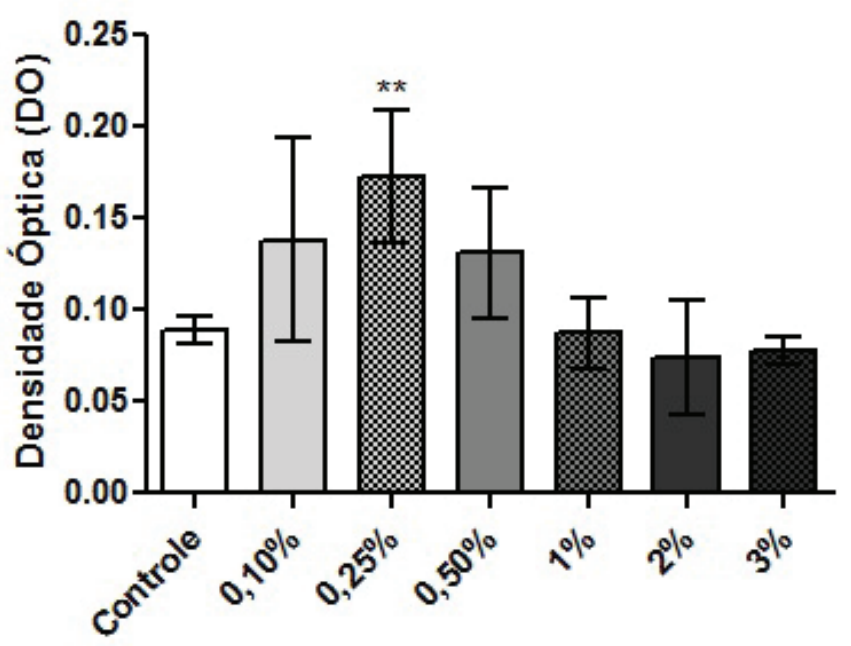

\section{Concentração $\mathrm{NaCl}$}

Fig.3. Interferência na formação do biofilme de Aeromonas spp. nas diferentes concentrações de $\mathrm{NaCl}: 0,1 ; 0,25 ; 0,5 ; 1 ; 2$ e 3\%, quando comparados ao controle. Os dados são apresentados com média + desvio padrão e as diferenças entre os grupos foram comparadas usando One-way ANOVA com pós-teste Tukey. **Nível de significância p<0,01. 

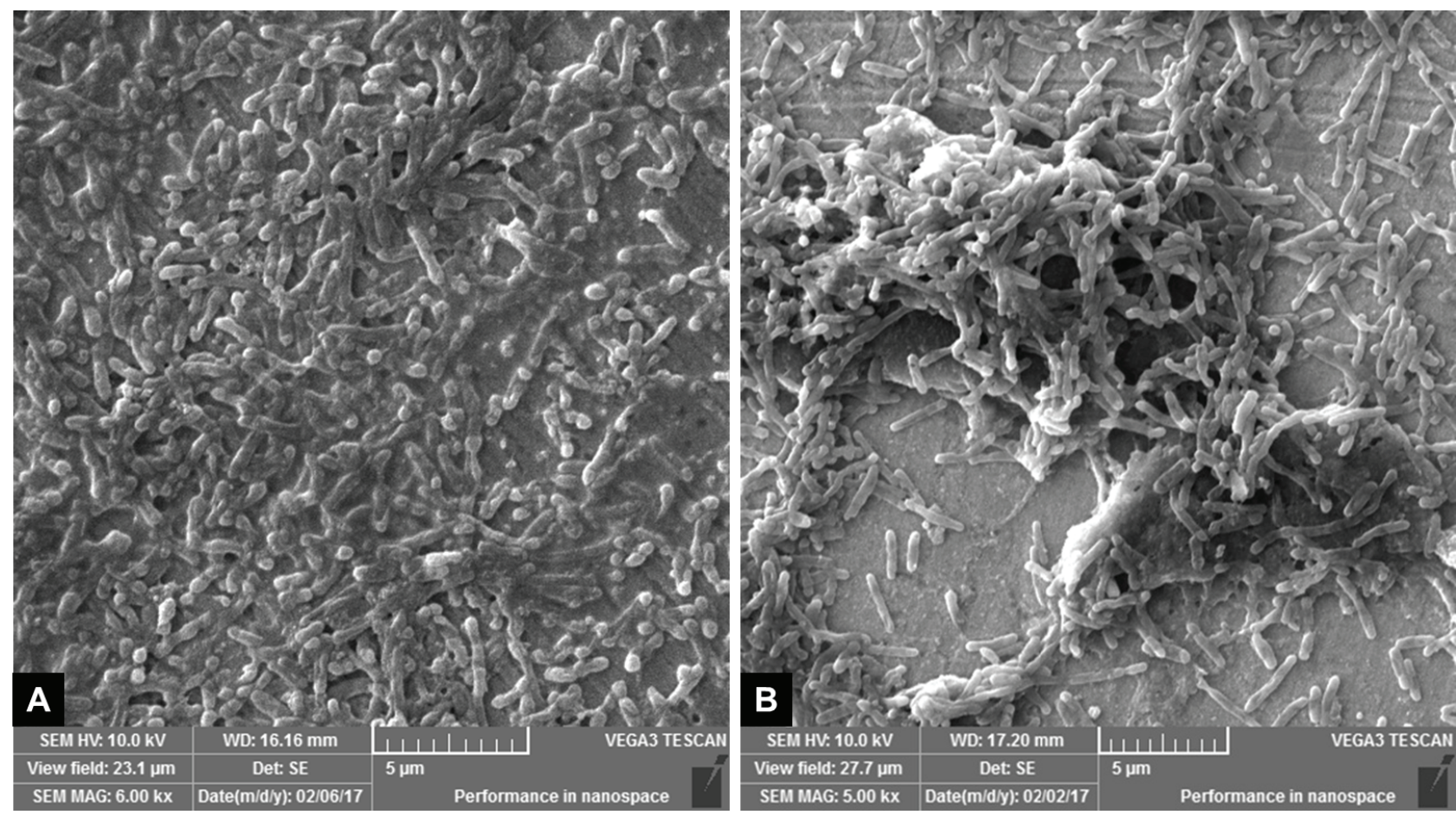

Fig.4. Microscopia eletrônica de varredura de Aeromonas spp. (A) sem nenhuma intervenção e (B) com adição de NaCl a 0,25\%. (A) Amostra controle (Aeromonas spp.) previamente caracterizada com fraca formação de biofilme, evidenciando as colônias bacterianas em estado de fraca produção. (B) As mesmas bactérias após o contato de $\mathrm{NaCl}$ a 0,25\%, previamente caracterizadas com moderada produção de biofilme, realçando um maior agrupamento das células quando comparadas a amostra controle.

aureus (Lim et al. 2004, Jubelin et al. 2005, Jensen et al. 2007, $\mathrm{Xu}$ et al. 2010.). Os autores Birrer et al. (2012) relataram que a diminuição da salinidade aumenta a sobrevivência e virulência de Vibrio spp. De acordo com Jahid et al. (2015), as bactérias tentam se adaptar às mudanças de osmolaridade e, além de induzirem a produção do biofilme, acumulam solutos orgânicos para equilibrar a baixa atividade da água e tolerar o estresse osmótico. Dessa forma, infecções bacterianas em níveis de $0,1 \%$ a $0,5 \%$ de salinidade, tendem a ser mais resistentes, uma vez que favorecem a formação do biofilme.

Os maiores níveis de salinidade não demonstraram nenhuma interferência na formação de biofilme, uma vez que as bactérias perdem sua capacidade de aderência a medida que maiores concentrações de $\mathrm{NaCl}$ são obtidas. Os autores Jahid et al. (2015) relataram que na concentração de $3 \%$ de $\mathrm{NaCl}$, a formação de biofilme foi reprimida. Casabianca et al. (2015), ao submeter diferentes isolados de $A$. hydrophila a cultivo apenas em água marinha (concentração de sal de 3\%) por 10 dias, verificou redução na produção de biofilme e aderência. Para se esquivar do estresse osmótico, as bactérias usufruem de sistemas de osmorregulação e buscam alternativas que contribuam para sua sobrevivência. Porém, além da salinidade, outros fatores devem ser levados em conta, como as condições ambientais, como temperatura, $\mathrm{pH}$ e disposição de nutrientes.

\section{Polipirrol}

CIM e CBM. A determinação da sensibilidade in vitro das amostras de Aeromonas spp. testadas com o polipirrol foi observada a partir da CIM e CBM. Entre as bactérias testadas para o ensaio de atividade antibacteriana, todas apresentaram sensibilidade a essa substância. Segundo Wong et al. (1994), cargas positivas são formadas ao longo da cadeia de PPy ocasionando uma forte interação eletrostática entre espécies de cargas opostas, inibindo o crescimento bacteriano. Esse composto interage com a célula bacteriana promovendo a fuga de componentes intracelulares (Silva Junior et al. 2016). Sendo assim, essa potencialidade da substância foi demonstrada em todas as cepas bacterianas utilizadas neste estudo, provocando a inibição do crescimento bacteriano. A CIM e a CBM da substância nesses isolados foi de $125 \mu \mathrm{g} / \mathrm{mL}$. De acordo com Silva Junior et al. (2016), o uso de polipirrol altamente solúvel como agente bactericida é eficaz tanto para as bactérias Gram positivas, como Staphylococcus aureus, quanto para as Gram negativas (Escherichia coli e Klebsiella pneumoniae). Da mesma forma, um estudo realizado por Varesano et al. (2013) constatou propriedades antibacterianas do PPy em E. coli. Portanto, mesmo as bactérias mais patogênicas são sensíveis a essa alternativa antimicrobiana.

Os autores Patil et al. (2016) encontraram uma forte correlação entre a aquicultura, diversidade de espécies de Aeromonas e resistência aos antibióticos. A presença de antibióticos no ambiente aquático favorece a agregação celular, levando à produção de biofilme e a troca de fatores de resistência entre micro-organismos aquáticos, entre eles, A. hydrophila (Corno et al. 2014). Isso reforça a importância de estudos alternativos para o controle dessas bactérias consideradas altamente resistentes, principalmente em ambientes aquáticos. Com a disseminação súbita desses micro-organismos através da água e consequentemente, a 
dispersão da resistência, outras alternativas têm sido buscadas para limitar essa patogenicidade.

Para evidenciar tais resultados, realizou-se a microscopia eletrônica de varredura, onde observou-se que o PPy não alterou a morfologia bacteriana quando colocado no valor de 0,5 CBM. Entretanto, a substância foi capaz de diminuir a quantidade de bactéria e foi, de fato, eficaz na morte dessas, na concentração de $125 \mu \mathrm{g} / \mathrm{mL}$ (Fig.5).

Dessa forma, o uso do PPy pode contribuir na eficácia dos antibióticos convencionais uma vez que, mesmo diluído na concentração de $125 \mu \mathrm{g} / \mathrm{mL}$, pode atuar como um agente antibacteriano. Além disso, é uma substância que possui diversas vantagens, por não apresentar nenhum tipo de toxicidade sobre os organismos dos animais (Wang et al. 2004), sendo considerado um potente polímero biocompatível (Chougule et al. 2011). Assim, uma possibilidade de uso dessa substância seria em tanques de criatórios de peixes ou nas próprias rações, uma vez que o PPy não apresenta um efeito citotóxico para os animais.

\section{Ensaio de motilidade}

No ensaio realizado com o PPy, as concentrações mais baixas (0,25 a 1\%), apresentaram crescimento bacteriano. Porém, o halo de migração nas placas contendo a substância, foi bem menor quando comparado às placas contendo a amostra controle. As concentrações de 0,1\% a 1\% apresentaram em média um halo de motilidade de 3,1, 2,4, 1,5 e 1,3 cm, respectivamente (Fig.6A). Quando comparados a amostra controle, houve uma diminuição significativa desse halo quando submetidos ao cultivo em meio contendo polipirrol. Apenas na concentração de $0,1 \%$ de PPy, não verificou-se diferença estatística $(p>0,05)$. Enquanto, nas concentrações mais altas (2 e 3\%) não houve crescimento dos isolados (Fig.6B).

Nas concentrações de 2 a 3\% não observou-se motilidade, provavelmente porque essa substância pode atuar como um agente bactericida (Wong et al. 1994), impedindo assim, o crescimento da bactéria e consequentemente, a não visualização da mesma. Entretanto, de acordo com Merino et al. (2006), vários genes estão envolvidos na síntese e expressão de flagelos e motilidade em Aeromonas, podendo ocasionar a presença de um flagelo inviável. Dessa forma, o ensaio pode não ser fenotipicamente expresso. Outros aspectos que devem ser considerados são as condições nas quais o ensaio foi realizado. Segundo Tremblay \& Deziel (2008), a migração bacteriana pode ter intervenção de alguns parâmetros como a temperatura de incubação, quantidade de ágar em cada amostra, pH e tempo de secagem sob o fluxo laminar.

Interferência na formação do biofilme. 0 polipirrol não interferiu na formação do biofilme bacteriano. Apesar de ser um potente agente antibacteriano, ele não foi capaz de inibir ou diminuir a formação do biofilme. Segundo Silva Junior et al. (2016), o comportamento antibacteriano do polipirrol depende de uma diversidade de parâmetros estruturais, tais como a área de superfície, nível de agregação das partículas e aditivos utilizados. Segundo Tomas (2012), as condições ambientais são fatores cruciais para as bactérias se locomoverem de forma livre ou permanecer aderidas formando colônias. Em A. hydrophila o desenvolvimento de enfermidades resulta de uma associação de fatores de virulência que contribui de forma acumulativa (Rasmussen-Ivey et al. 2016). Já os autores

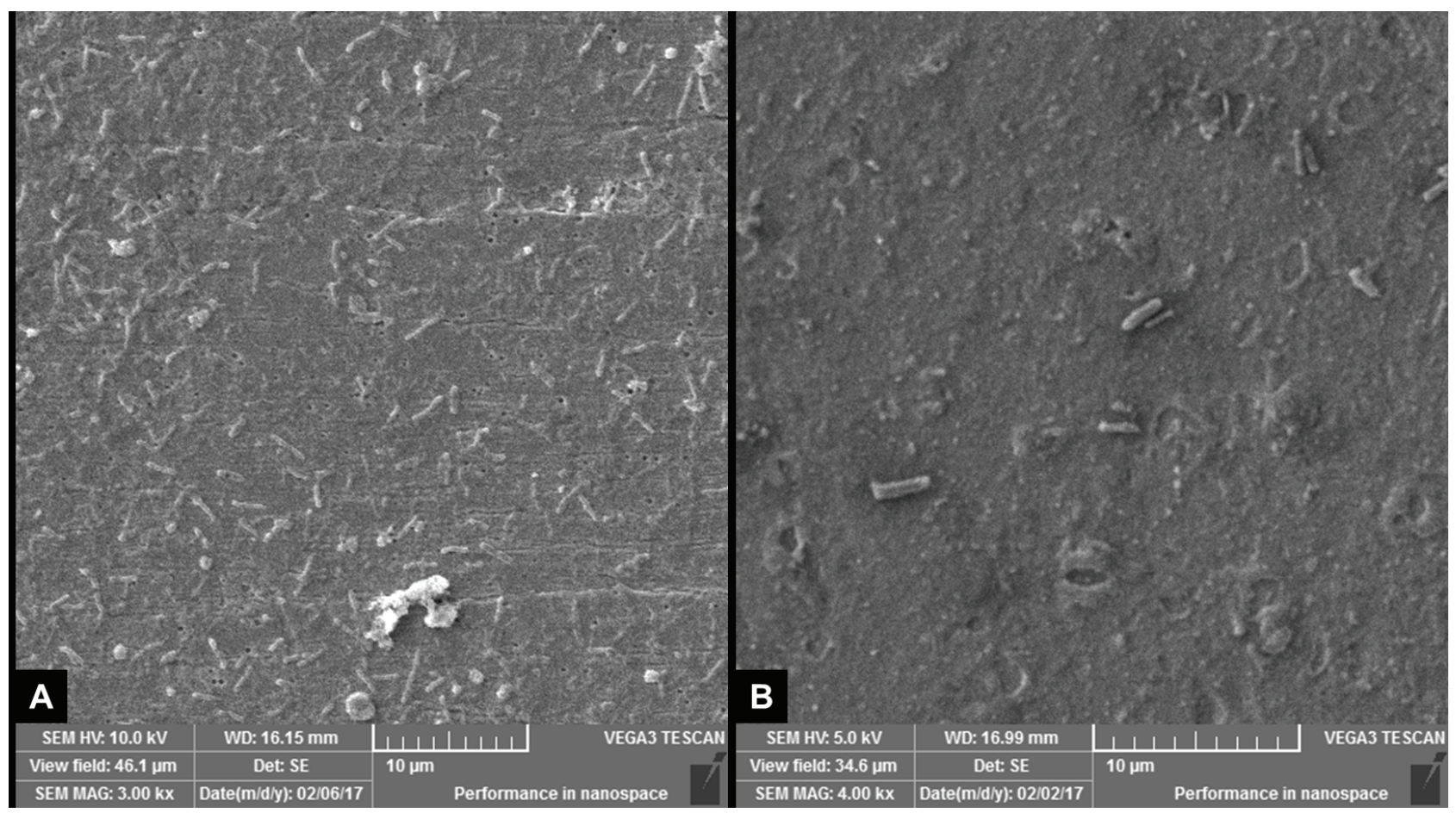

Fig.5. Microscopia eletrônica de varredura de Aeromonas spp. nos valores de (A) 0,5 CBM e (B) CBM do polipirrol. (A) Bastonetes Gram negativos característicos de Aeromonas spp. evidenciando que o PPy em 0,5 CBM $(62,5 \mu \mathrm{g} / \mathrm{mL})$ não alterou a morfologia da bactéria. (B) Considerável diminuição dessas bactérias, realçando a eficácia da substância contra esse micro-organismo (seta) na concentração de $125 \mu \mathrm{g} / \mathrm{mL}$. 


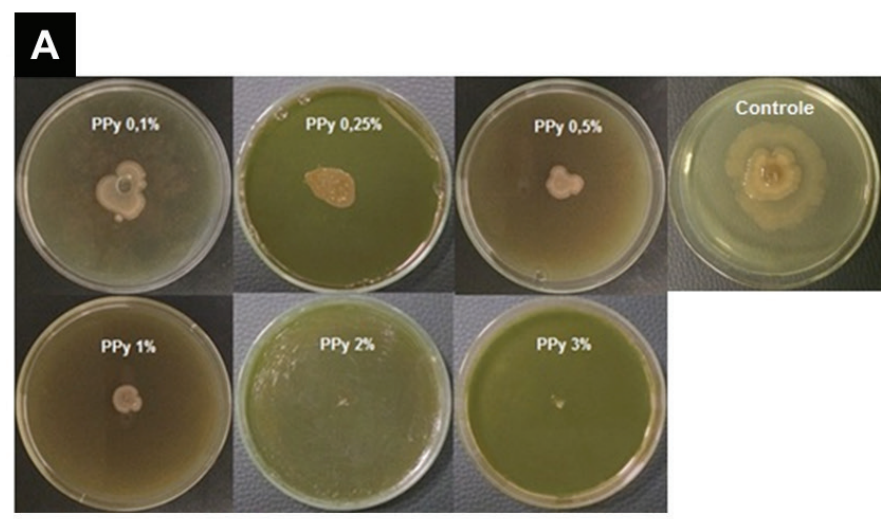

B

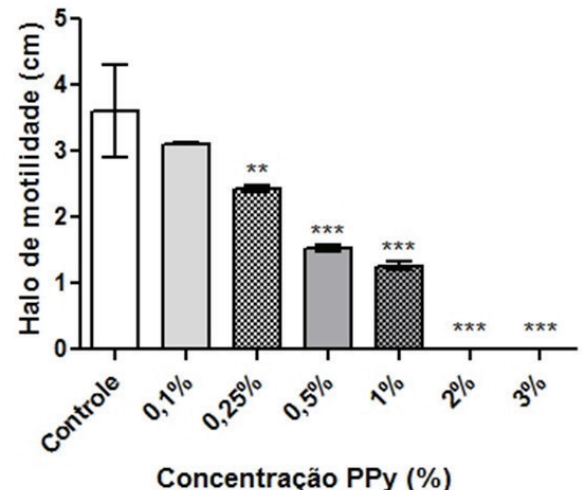

Fig.6. Ensaio de motilidade das bactérias Aeromonas spp. que carream o gene fla, na presença de diferentes concentrações de PPy: 0,1; 0,$25 ; 0,5 ; 1 ; 2$ e 3\%, respectivamente. (A) Análise fenotípica do halo de motilidade dos isolados de Aeromonas spp., evidenciando a migração dessas bactérias a partir do local inoculado. (B) Halo de motilidade (cm) da média dos isolados de Aeromonas spp. em função das diferentes concentrações de PPy quando comparados ao controle (sem a substância). Os dados são apresentados com média + desvio padrão e as diferenças entre os grupos foram comparadas usando One-way ANOVA com pós-teste Tukey. Nível de significância: ${ }^{* *} \mathrm{p}<0,01 ;{ }^{* * *} \mathrm{p}<0,001$.

Zheng et al. (2013) relataram o uso de PPy como um sensor in situ para detecção e controle do biofilme. Porém, essa detecção depende de diversos processos, como a acumulação das bactérias durante o crescimento, disponibilidade de nutriente, temperatura, entre outros.

\section{CONCLUSÕES}

As concentrações de 2 e $3 \%$ de $\mathrm{NaCl}$ foram capazes de inibir a motilidade das bactérias que carreavam o gene fla. Além disso, os níveis de salinidade interferiram na formação do biofilme bacteriano, na qual a concentração de $0,25 \%$ evidenciou uma maior formação de biofilme dos isolados de Aeromonas spp. Dessa forma, animais que vivem em água salobra tendem a ter mais infecções causadas por essas bactérias.

0 uso de polipirrol como agente bactericida introduz vantagens como alternativa para melhorar a eficácia da antibioticoterapia na aquicultura, uma vez que, mesmo diluído, foi capaz de provocar a morte bacteriana em uma concentração de $125 \mu \mathrm{g} / \mathrm{mL}$.
A substância reduziu a motilidade de Aeromonas nas concentrações de 0,25 a $3 \%$, diminuindo assim, a patogenicidade bacteriana. Dessa forma, seu uso tem o potencial de reduzir o impacto das infecções ocasionadas por esse micro-organismo e consequentemente, a perda econômica na piscicultura.

\section{REFERÊNCIAS}

Birrer S.C., Reusch T.B. \& Roth O. 2012. Salinity change impairs pipefish immune defence. Fish Shellfish Immunol. 33(6):1238-1248. http://dx.doi. org/10.1016/j.fsi.2012.08.028. PMid:22982326.

Casabianca A., Orlandi C., Barbieri F., Sabatini L., Di Cesare A., Sisti D., Pasquaroli S., Magnani M. \& Citterio B. 2015. Effect of starvation on survival and virulence expression of Aeromonas hydrophila from different sources. Arch. Microbiol. 197(3):431-438. <http://dx.doi.org/10.1007/s00203-0141074-Z><PMid:25533849>

Ceri H., Olson M.E. \& Turner R.J. 2010. Needed, new paradigms in antibiotic development. Exp. Opin. Pharmac. 11(8):1233-1237. <http://dx.doi. org/10.1517/14656561003724747><PMid:20384540>

Chougule M.A., Pawar S.G., Godse P.R., Mulik R.N., Sen S. \& Patil V.B. 2011. Synthesis and characterization of polypyrrole (PPy) thin films. Soft Nanosc. Letters 1(1):6-10.

Christensen G.D., Simpson W.A., Younger J.J., Baddour L.M., Barrett F.F., Melton D.M. \& Beachey E.H. 1985. Adherence of coagulase-negative staphylococci to plastic tissue culture plates: a quantitative model for the adherence of staphylococci to medical devices. J. Clin. Microbiol. 22(6):996-1006. <PMid:3905855>

CLSI 2014. M100-S24: Performance Standards for Antimicrobial Susceptibility Testing. Vol.34, No.1. 24th ed. Clinical and Laboratory Standard Institute, Wayne, Pennsylvania.

Clutterbuck A.L., Woods E.J., Knottenbelt D.C., Clegg P.D., Cochrane C.A. \& Percival S.L. 2007. Biofilms and their relevance to veterinary medicine. Vet. Microbiol.121(1/2):1-17.<http://dx.doi.org/10.1016/j.vetmic.2006.12.029> $<$ PMid:17276630>

Corno G., Coci M., Giardina M., Plechuk S., Campanile F. \& Stefani S. 2014. Antibiotics promote aggregation within aquatic bacterial communities. Front. Microbiol. 5:297. <http://dx.doi.org/10.3389/fmicb.2014.00297> <PMid:25071728>

Delamare A.P.L., Dalcin T., Muller G., Costa S.O.P.\& Echeverrigaray S. 2003. The effect of organic osmoprotectors on Aeromonas trota and A. hydrophila grown under high sodium chloride concentrations. Braz. J. Microbiol. 34(Suppl.1):128-130. <http://dx.doi.org/10.1590/S1517-83822003000500044>

FAO 2016. The State of World Fisheries and Aquaculture: contributing to food security and nutrition for all. Food and Agriculture Organization, Rome. 200p.

Freitas V.R., Van der Sand S.T. \& Simonetti A.B. 2010. In vitro biofilm formation by Pseudomonas aeruginosa and Staphylococcus aureus on the surface of high-speed dental handpieces. Revta Odontol. Unesp 39(4):193-200.

Gram L., Melchiorsen J., Spanggaard B., Huber I. \& Nielsen T.F. 1999. Inhibition of Vibrio anguillarum by Pseudomonas fluorescens AH2, a possible probiotic treatment of fish. Appl. Environ. Microbiol. 65(3):969-973.<PMid:10049849>

Huang L., Qin Y., Yan Q., Lin G., Huang L., Huang B. \& Huang W. 2015. MinD plays an important role in Aeromonas hydrophila adherence to Anguilla japonica mucus. Gene 565(2):275-281. <http://dx.doi.org/10.1016/j. gene.2015.04.031><PMid:25881868>

Jacques M., Aragon V. \& Tremblay Y.D.N. 2010. Biofilm formation in bacterial pathogens of veterinary importance. Anim. Health Res. Rev. 11(2):97-121. <http://dx.doi.org/10.1017/S1466252310000149><PMid:20969814>

Jahid I.K., Mizan M.F.R., Ha A.J. \& Ha S.D. 2015. Effect of salinity and incubation time of planktonic cells on biofilm formation, motility, exoprotease production, and quorum sensing of Aeromonas hydrophila. Food Microbiol. 49:142-151. <http://dx.doi.org/10.1016/j.fm.2015.01.016> <PMid:25846924> 
Janda J.M. \& Abbott S.L. 2010. The genus Aeromonas: taxonomy, pathogenicity, and infection. Clin. Microbiol. Rev. 23(1):35-73.<http://dx.doi.org/10.1128/ CMR.00039-09><PMid:20065325>

Jensen A., Larsen M.H., Ingmer H., Vogel B.F. \& Gram L. 2007. Sodium chloride enhances adherence and aggregation and strain variation influences invasiveness of Listeria monocytogenes strains. J. Food Protect. 70(3):592599. <http://dx.doi.org/10.4315/0362-028X-70.3.592><PMid:17388046>

Jubelin G., Vianney A., Beloin C., Ghigo J.M., Lazzaroni J.C., Lejeune P. \& Dorel C. 2005. CpxR/OmpR interplay regulates curli gene expression in response to osmolarity in Escherichia coli. J. Bacteriol. 187(6):2038-2049. <http://dx.doi. org/10.1128/JB.187.6.2038-2049.2005><PMid:15743952>

Kang T.S., Lee S.W., Joo J. \& Lee J.Y. 2005. Electrically conducting polypyrrole fibers spun by electrospinning. Synth. Metals 153(1/3):61-64. <http:// dx.doi.org/10.1016/j.synthmet.2005.07.135>

Kirov S.M., Tassell B.C., Semmler A.B., O’Donovan L.A., Rabaan A.A. \& Shaw J.G. 2002. Lateral flagella and swarming motility in Aeromonas species. J. Bacteriol. 184(2):547-555. <http://dx.doi.org/10.1128/JB.184.2.547555.2002> <PMid:11751834>

Kubitza F., Campos J.L., Ono E.A. \& Istchuk P.I. 2012. Panorama da piscicultura no Brasil. Panorama da Aquicultura 132(22):14-25.

Kuchma S.L., Delalez N.J., Filkins L.M., Snavely E.A., Armitage J.P. \& O’Toole G.A. 2015. Cyclic Di-GMP-mediated repression of swarming motility by Pseudomonas aeruginosa PA14 requires the motab stator. J. Bacteriol. 197(3):420-430. <http://dx.doi.org/10.1128/JB.02130-14> <PMid:25349157>

Li J., Ni X.D., Liu Y.J. \& Lu C.P. 2011. Detection of three virulence genes alt, ahp and aerA in Aeromonas hydrophila and their relationship with actual virulence to zebra_ish. J. Appl. Microbiol. 110(3):823-830. <http://dx.doi. org/10.1111/j.1365-2672.2011.04944.X><PMid:21219556>

Lim Y., Jana M., Luong T.T. \& Lee C.Y. 2004. Control of glucose- and NaCl-induced biofilm formation by rbf in Staphylococcus aureus. J. Bacteriol. 186(3):722-729. <http://dx.doi.org/10.1128/JB.186.3.722-729.2004> <PMid:14729698>

Lowry R., Balboa S., Parker J.L. \& Shaw J.G. 2014. Aeromonas flagella and colonisation mechanisms. Adv. Microb. Physiol. 65:203-256. <http://dx.doi. org/10.1016/bs.ampbs.2014.08.007> <PMid:25476767>

Marcel K.A., Antoinette A.A. \& Mireille D. 2002. Isolation and characterization of Aeromonas species from an eutrophic tropical estuary. Marine Pollution Bull. 44(12):1341-1344. <http://dx.doi.org/10.1016/S0025-326X(02)00143-1> <PMid:12523537>

Martin-Carnahan A. \& Joseph S.W. 2005. Family I: Aeromonadaceae, p.556. In: Brenner D.J., Krieg N.R. \& Staley J.T., Bergey's Manual Systematic Bacteriology. Vol.2, Part B. 2nd ed. Springer, Berlin.

Merino S., Shaw J.G. \& Tomás J.M. 2006. Bacterial lateral flagella: an inducible flagella system. FEMS Microbiol. Letters 263(2):127-135. <http://dx.doi. org/10.1111/j.1574-6968.2006.00403.x><PMid:16978346>

Naviner M., Gordon L., Giraud E., Denis M., Mangion C., Le Bris H. \& Ganière J.-P. 2011. Antimicrobial resistance of Aeromonas spp. isolated from the growth pond to the commercial product in a rainbow trout farm following a flumequine treatment. Aquaculture 315(3-4):236-241. <http://dx.doi. org/10.1016/j.aquaculture.2011.03.006>

Nostro A., Procopio F., Pizzimenti F.C., Cannatelli M.A., Bisignano G., Marino A., Blanco A.R., Cioni P.L. \& Roccaro A.S. 2007. Effects of oregano, carvacrol and thymol on Staphylococcus aureus and Staphylococcus epidermidis biofilms. J. Med. Microbiol. 56(4):519-523.<http://dx.doi.org/10.1099/jmm.0.46804$0><$ PMid:17374894>

Patil H.J., Benet-Perelberg A., Naor A., Smirnov M., Ofek T., Nasser A., Minz D. \& Cytryn E. 2016. Evidence of increased antibiotic resistance in phylogenetically-diverse Aeromonas isolates from semi-intensive fish ponds treated with antibiotics. Front. Microbiol. 7:1875. <http://dx.doi. org/10.3389/fmicb.2016.01875><PMid:27965628>

Pereira A.A., Araújo E.A., Ribeiro L., Passos F.R., Botrel D.A., Bernardes P.C. \& Andrade N.J.D. 2013. Otimização da produção de nanopartículas de prata utilizando nova síntese e avaliação da sua ação sanitizante. Biosci. J. 29(2):506-515.
Pianetti A., Manti A., Boi P., Citterio B., Sabatini L., Papa S., Rocchi M.B.L. \& Bruscolini F. 2008. Determination of viability of Aeromonas hydrophila in increasing concentrations of sodiumchloride at different temperatures by flowcytometry and plate count technique. Int. J. Food Microbiol. 127(3):252-260. <http://dx.doi.org/10.1016/j.ijfoodmicro.2008.07.024><PMid:18765166>

Pianetti A., Battistelli M., Barbieri F., Bruscolini F., Falcieri E., Manti A., Sabatini L. \& Citterio B. 2012. Changes in adhesion ability of Aeromonas hydrophila during long exposure to salt stress conditions. J. Appl. Microbiol. 113(4):974-982. <http://dx.doi.org/10.1111/j.1365-2672.2012.05399.x><PMid:22805151>

Rasmussen-Ivey C.R., Figueras M.J., McGarey D. \& Liles M.R. 2016. Virulence factors of Aeromonas hydrophila: in the wake of reclassification. Front. Microbiol. 7:1337.<http://dx.doi.org/10.3389/fmicb.2016.01337><PMid:27610107>

Santos P.G., Santos P.A., Bello A.R. \& Freitas-Almeida A.C. 2011. Association of Aeromonas caviae polar and lateral flagella with biofilm formation. Lett. Appl. Microbiol. 52(1):49-55.<http://dx.doi.org/10.1111/j.1472-765X.2010.02965. $\mathrm{x}><$ PMid:21118278>

Schulze A.D., Alabi A.O., Tattersall-Sheldrake A.R. \& Miller K.M. 2006. Bacterial diversity in a marine hatchery: Balance between pathogenic and potentially probiotic bacterial strains. Aquaculture 256(1/4):50-73. <http://dx.doi. org/10.1016/j.aquaculture.2006.02.008>

Silva Junior F.A.G., Queiroz J.C., Macedo E.R., Fernandes A.W.C., Freire N.B., Costa M.M. \& Oliveira H.P. 2016. Antibacterial behavior of polypyrrole: the influence of morphology and additives incorporation. Materials Sci. Eng. C 62:317322. <http://dx.doi.org/10.1016/j.msec.2016.01.067><PMid:26952429>

Tiba M.R., Nogueira G.P. \& Leite D.S. 2009. Estudo dos fatores de virulência associados à formação de biofilme e agrupamento filogenético em Escherichia coli isoladas de pacientes com cistite. Revta Soc. Bras. Med. Trop. 42(1):5862. <http://dx.doi.org/10.1590/S0037-86822009000100012>

Tomás J.M. 2012. The main Aeromonas pathogenic factors. Int. School Res. Network Microbiol. 2012:1-22. <PMid:23724321>

Tremblay J. \& Déziel E. 2008. Improving the reproducibility of Pseudomonas aeruginosa swarming motility assays. J. Basic Microbiol. 48(6):509-515. <http://dx.doi.org/10.1002/jobm.200800030> <PMid:18785657>

Varesano A., Vineis C., Tonetti C., Mazzuchetti G. \& Bobba V. 2015. Antibacterial property on Gram-positive bacteria of polypyrrole-coated fabrics. J. Appl. Polym. Sci. 132:41670.

Varesano A., Vineis C., Aluigi A., Rombaldoni F., Tonetti C. \& Mazzuchetti G. 2013. Antibacterial efficacy of polypyrrole in textile applications. Fibers and Polymers 14(1):36-42. <http://dx.doi.org/10.1007/s12221-013-0036-4>

Wang X., Gu X., Yuan C., Chen S., Zhang P., Zhang T., Yao J., Chen F. \& Chen G. 2004. Evaluation of biocompatibility of polypyrrole in vitro and in vivo. J. Biomed. Mater. Res. A 68A(3):411-422. <http://dx.doi.org/10.1002/ jbm.a.20065><PMid:14762920>

Wong J.Y., Langer R. \& Ingber D.E. 1994. Electrically conducting polymers can noninvasively control the shape and growth of mammalian cells. Proc. Natl Acad. Sci. 91(8):3201-3204. <http://dx.doi.org/10.1073/pnas.91.8.3201> <PMid:8159724>

Wu H., Moser C., Wang H.Z., Hoiby N. \& Song Z.J. 2015. Strategies for combating bacterial biofilm infections. Int. J.Oral Sci. 7(1):1-7.<http://dx.doi.org/10.1038/ ijos.2014.65><PMid:25504208>

Xu H., Zou Y., Lee H.Y. \& Ahn J. 2010. Effect of $\mathrm{NaCl}$ on the biofilm formation by foodborne pathogens. J. Food Sci. 75(9):580-585. <http://dx.doi. org/10.1111/j.1750-3841.2010.01865.x><PMid:21535614>

Zhang J., Neoh K.G., Hu X. \& Kang E.T. 2014. Mechanistic insights into response of Staphylococcus aureus to bioelectric effect on polypyrrole/chitosan film. Biomaterials 35(27):7690-7698. <http://dx.doi.org/10.1016/j. biomaterials.2014.05.069><PMid:24934644>

Zheng L.Y., Congdon R.B., Sadik O.A., Marques C.N.H., Davies D.G., Sammakia B.G., Lesperance L.M. \& Turner J.M. 2013. Electrochemical measurements of biofilm development using polypyrrole enhanced flexible sensors. Sensors and Actuators B, Chemical 182:725-732. <http://dx.doi.org/10.1016/j. snb.2013.03.097> 